\title{
La evolución arquitectónica de la iglesia de Sant Vicenç de Rus (Castellar de N'hug, Barcelona) durante el período medieval: resultados de las excavaciones
}

\author{
ALBERTO LOPEZ MULLOR * \\ Álvar CAIXAL *
}

Durante los años 1983, 1985 y 1986 hemos desarrollado campañas de excavación en la iglesia de Sant Vicenç de Rus, que han afectado toda la superficie interna y el entorno inmediato '. El objetivo de estos trabajos era poner en evidencia las diferentes fases de utilización que ha tenido el templo, y averiguar los rasgos fundamentales de su historia, todo ello como paso previo a la restauración del edificio.

Como buena parte de la documentación que se refiere al yacimiento ya ha sido publicada ${ }^{2}$, no aludiremos excesivamente a este aspecto, aunque lógicamente lo hemos tenido en cuenta para la elaboración de nuestras conclusiones. Los resultados obtenidos, por periodos cronológicos, se pueden sintetizar del siguiente modo:

* Servicio de Patrimonio Arquitectonico. Diputación de Barcelona.

Un avence de estos trabajos puede verse en LOPEZ MULLOR 1984C: 177-180; Idem 1985: 179-185; LOPEZ MULLOR, 1989.

2 SUREDA 1984: 176-177. 
PRIMERA FASE (ca. 950-1106, láms. I" y III)

El año 961 el nombre de Rus aparece en las fuentes por primera vez ${ }^{3}$. Sin embargo, la iglesia no es citada hasta el 983, con motivo de la consagración del templo del monasterio de San Llorenç prop Bagá (Guardiola de Berguedà), situado a pocos kilómetros ${ }^{4}$. Estas fechas se han ido confirmando a lo largo de nuestros trabajos.

Durante la excavación se ha localizado una necrópolis de inhumación que rodeaba los muros de edificio. Este primer momento de la sagrera del templo se caracteriza por la presencia de tumbas excavadas en la roca arenisca, cuyo resumen tipológico es como sigue: quince antropomorfas, nueve fusiformes o elipsoidales, dos trapezoidales, una rectangular y seis de forma poco definida ${ }^{5}$. De un total de treinta y tres, veintisiete pertenecen a adultos y seis son infantiles.

Si reparamos en su tipología, podemos observar grupos concretos. Las tumbas antropomorfas, en general, son homogéneas, nueve tienen cabecera cuadrada - unidades estratigráficas 39, 71, 149, 170, 173, 246, 248, 262 y 277-; una la tiene rectangular -u.e. 151-, y cinco redondeada -u.e. 69, 238, 249, 281 y 302-. Estas distinciones podrían dar precisiones cronológicas, pues, teóricamente, las sepulturas de cabecera redondeada son más antiguas que las de cabecera cuadrada o rectangular $^{6}$. No obstante, pensamos que la naturaleza del terreno donde fueron practicadas tiene mucho que ver con su forma. De esta manera, la número 69, de cabecera redondeada, aprovechó una diaclasa de la roca, lo que seguramente condicionó el trazado de su perimetro que, visto en planta, sin tener en cuenta esta circunstancia, resuelta paradigmático. En los casos de las sepulturas 238, 249, la menos típica, y 302 , la situación es muy parecida, aunque las dos primeras se hallan agrupadas ante la puerta del templo, y tal disposición pudiera hacer pensar que son más antiguas que el resto o tienen alguna caracteristica peculiar?

Por lo que se refiere a las sepulturas antropomorfas con cabecera cuadrada o rectangular, su característica más generalizada es la inexactitud del perímetro, debido a que la roca virgen es bantante blanda y no

\footnotetext{
SUREDA 1984: 176

Baraut 1979: 102-105.

Bolos, Pages, 1982: 59-97.

Bolos, Pagès, 1982: 80.

RIU 1982: 29-51.
} 

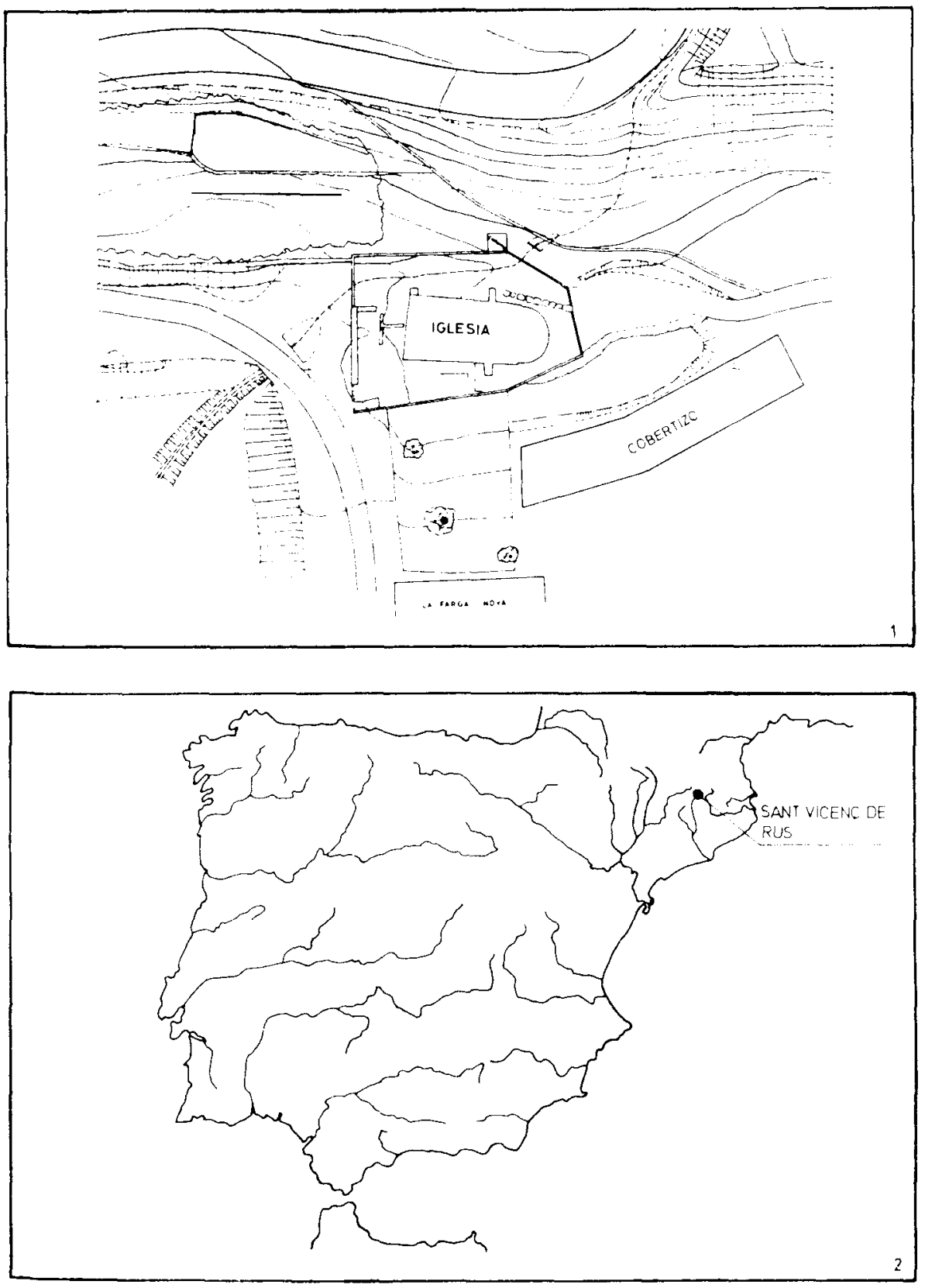

Lámina I. 1. Situación topográfica de la iglesia, 2. Localización del yacimiento en la Peninsula Ibérica. 


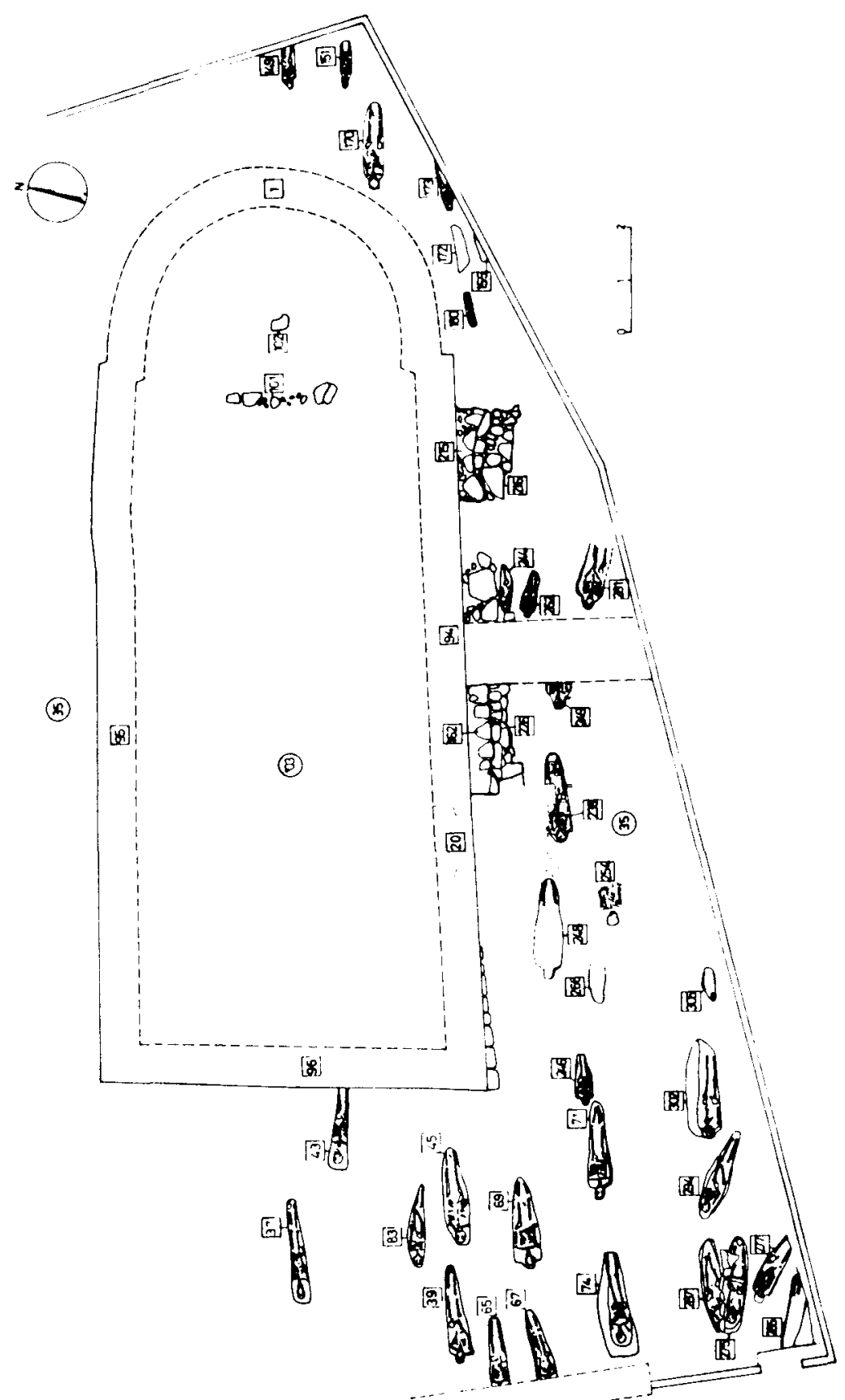

Lámina Il. Planta del templo del siglo $\mathrm{x}$ y de la fase contemporánea de la necrópolis. 


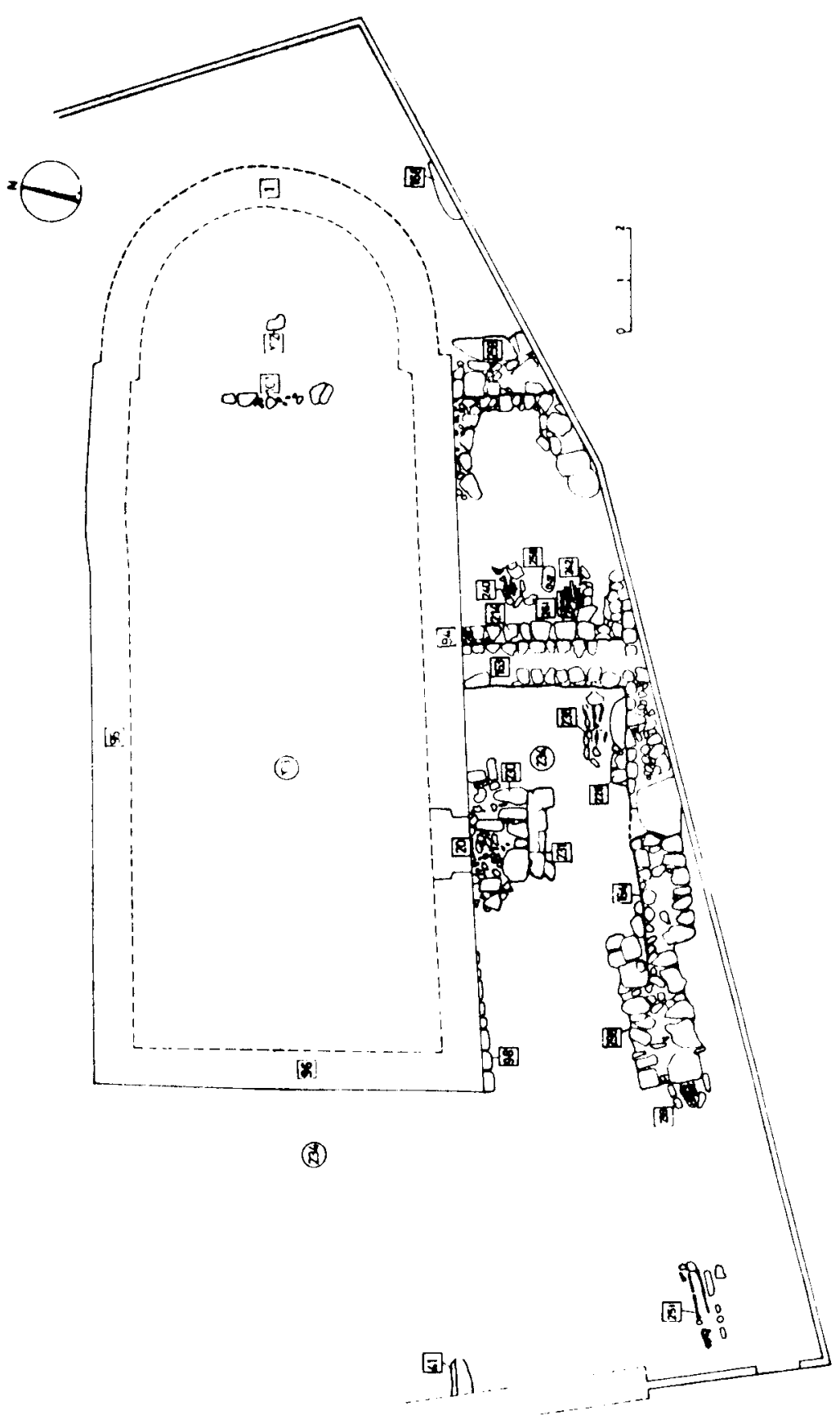

Lámina III. Planta de la iglesia en el siglo xi. Nótese las ruinas del pórtico adosado a la fachada sur. 
permitió recortalas perfectamente. Si atendemos a las agrupaciones, veremos que existen tumbas de este tipo a poniente y levante del edificio, y también en el ángulo suroeste. En el este, casi todas son antropomorfas, en el oeste se concentran mucho las fusiformes y trapezoidales, supuestamente más antiguas. En definitiva pensamos que esta dispersión indica que toda la sagrera fue utilizada al mismo tiempo.

No se han localizado todas las cubiertas de las sepulturas, pues algunas fueron reutilizadas hasta épocas muy recientes ${ }^{8} \mathrm{y}$, logicamente, perdieron su cerramiento original. A pesar de ello, la excavación ha demostrado que consistian en losas y piedras unidas en seco.

E análisis de las tumbas no antropomorfas es todavía más problemático. En principio, creemos que las inhumaciones infantiles no son demasiado significativas - u.e. 172, 173, 180, 244, 262 y 305-. Su escaso tamaño hace que se encuentren tan condicionadas por las irregularidades del terreno, que resultan casi inclasificables. Así, la número 172 tienen una apariencia rectangular, mientras que la número 173, es antropomorfa. Tanto la una como la otra, utilizan diaclasas de la roca, pero la número 172 está en una grieta tan pronunciada que acaso, no se consideró oportuno retocarla. La tumba número 180 , que también está en el ángulo sudeste del templo. es semejante.

Las sepulturas 244 y 262 , en el exterior de la fachada de mediodia, presentan una disposición muy caracteristica. La primera, que se halla materialmente sobre la cimentación del edificio, es elipsoidal, la segunda. algo más alejada, y menos condicionada por la estructura arquitectónica. es antropomorfa. Por último, la 305, totalmente aislada, aprovecha otra vez una grieta. A pesar de todo. y con muy buena voluntad. podriamos considerar que las tumbas más cercanas al templo son las más antiguas, y por ello no presentan morfologia antropomórfica. Es el caso de las número 172,180 y 244, pero las número 262 y 305 rompen claramente el esquema.

Por lo que concierne a los enterramientos de adultos no antropomorfos. el panorama tampoco es demasiado clarificador. La tumba trapezoidal número 43 está muy cerca de la fachada oeste, y sus pies rozan la cimentación. Detrás suyo están las número 37,45 y 83 , que parecen elipsoidales, aunque aprovechan grietas naturales. Un poco más atrás,

Dentro de la turnba número 45 , antropomorfa excavada en la roca, cuya cubierta era de piedras pequenas unidas con mortero. se halló una moneda de Felipe IV en la boca del inhumado 
encontramos las sepulturas antropomorfas número $39,69,71$ y 246 , teóricamente más tardias, pero una vez más se rompe la hipótesis de mayor antigüedad relacionada con la proximidad al templo, cuando encontramos en la cuarta hilera las tumbas número 74, 275 y 287. La primera de ellas trapezoidal y las otras dos fusiformes.

Todo esto nos hace considerar que, si bien existe una distinción tipológica elocuente entre las sepulturas excavadas, resulta muy difícil establecer una diacronía entre las mismas atendiendo a su posición física. Los únicos datos concretos que poseemos son: la cronología del estrato 103 del interior del templo, cifrada hacia mediados del siglo x; la fecha del estrato 229 del exterior situable sobre el primer cuarto del siglo XI, que cubría una serie de sepulturas; el ajuar de la tumba número 238, y la documentación referida al lugar desde el 961. Además, tenemos la evidencia de que la cimentación del porche de la fachada sur (infra). fechada por el citado estrato 229, corta la tumba número 249, aunque respeta - ¿por casualidad? - las número 262 y 281.

Con este conjunto de informaciones, podemos decir que la primera etapa del cementerio abarcó desde mediados del siglo $x$ hasta el primer cuarto del siglo XI aproximadamente. Esta cronología se ajusta bien a la datación de las tumbas antropomorfas, pero no a la fecha tradicional de las elipsoidales o fusiformes y las trapezoidales. Asi que, o suponemos que a lo largo del período cronológico ca. 950 - ca. 1025 todas estas tumbas se practicaron más o menos contemporáneamente, tal y como parece ocurrir en otros lugares ${ }^{9}$, o nos arriesgamos a alargar la cronología sin más argumentos que los tipológicos. Por ahora, la primera alternativa parece la más razonable.

Como acabamos de ver, las noticias documentales no se contradicen con los hallazgos realizados en la necrópois. Sin embargo, también puede asociarse a otras estructuras del yacimiento, que indican la localización y las características del primer recinto religioso. Si consideramos que las tumbas se colocaban invariablemente alrededor de los templos y nunca en su interior, podemos afirmar que la construcción original debía encontrarse cerca de las sepulturas descubiertas. Si además, tenemos en cuenta que en el interior del templo actual no hay ninguna tumba medieval, es lícito concluir que el primer edificio se encontraba donde hoy existe la iglesia románica. De este modo, podemos deducir que el

LOPEZ MULloR 1984 a: 95-101; Idem 1984 b: 136-140; Ídem 1984 d: 296-302; idem 1985: 532-540; FIERRO 1988: 433 
trazado de las paredes perimetrales actuales es el mismo que el de las más antiguas (poseemos otras evidencias estratigráficas, infra).

Teniendo en cuenta estas premisas, podemos afirmar que, al menos desde el siglo $x$, el templo constaba de nave única rectangular, encabezada por un ábside semicircular. El acceso se encontraba en la fachada de mediodía, y se realizaba a través de una puerta muy sencilla, acabada en arco de medio punto, situada algo más al oeste que la conservada hasta hoy. La cubierta, hemos de suponer que descansaba sobre una armadura de puntales de madera, apoyada sobre la parte superior de los muros, y que servía de soporte a las losas de pizarra que coronaban el sistema. Estos elementos no han llegado a nosotros, pero podemos deducir su existencia gracias a ciertos datos. El más importante es el grosor de las paredes del templo, no superior a $70 \mathrm{~cm}$, según se desprende de una cata realizada en la cimentación interna del muro meridional. A pesar de ellos, las paredes que ahora poseemos miden $114 \mathrm{~cm}$ de ancho. Este hecho se explica por las reformas que sufrió el templo en la fase siguiente, que después explicaremos.

En cuanto a la distribución interior, las excavaciones han evidenciado que, en el momento de la construcción, la iglesia no tenía más capilla que la principal. El pavimento - u.e 103- era de tierra batida y cumplia dos funciones: la de suelo del edificio y la de relleno regularizador de la roca natural, la cual presenta una ligera pendiente hacia el sur. Esta segunda función se planteó de tal manera que la parte más elevada de la roca virgen, situada al norte de la nave, se utilizó como suelo, después de haber sido alisada.

Por debajo del pavimento 103, aparecieron una serie de orificios de poste, principalmente en el tercio oriental de la nave. Indicaban la localización de los andamiajes empleados para la construcción de esta parte del templo. Debe destacarse que este primer suelo cubría la roca directamente y los agujeros de poste se encontraban también en el terreno virgen.

El estrato 103 contenia un conjunto de cerámicas grises y una pieza de pasta beige, que, como mínimo, pueden datarse en el siglo x. Además, disponemos de un terminus ante quem que ayuda a confirmar esta cronología: la decoración pictórica del ábside, descubierta en 1983, fechada en 1106 , coincidiendo con una consagración del templo ${ }^{10}$. Como veremos en la segunda fase, al adaptar la iglesia a los cánones románi-

10 Baraut 1978: 166. 
cos, se procedió el regruesamiento o a la reconstrucción de la pared del ábside. Esta operación implicó realizar una trinchera de fundación que cortó el estrato 103. Por ello debe deducirse que este estrato es anterior a 1106 y que se encontraba donde lo hemos hallado cuando se modifico la pared del ábside, que a continuación recibió los murales descubiertos.

En el área del presbiterio hemos localizado restos del altar - u.e. 102-, que indican su situación central. Tambien se ha descubierto una hilera de piedras, la unidad 101, que corresponderia al escalón terminal del santuario. Todo ello sobre el pavimento 103.

Desde un momento poco preciso del final de la primera fase, y hasta el principio de la tercera, funcionó en el exterior del templo un elemento arquitectónico. Se trataba de un porche, cuyos cimientos aparecieron durante la excavación. La cronología de su fundación no es muy exacta porque el pavimento interno - u.e. 234- sólo ha proporcionado cerámicas grises informes. Sin embargo, está claro que el supuesto pórtico es posterior al siglo $x$, ya que su cimentación cortaba la tumba antropomorfa 249. De este modo, podemos establecer un terminus post quem del siglo $\mathrm{x}$. Por otra parte, este pavimento funcionaba con el escalón de la puerta del templo - u.e. 231-, también posterior al momento inicial de la necrópolis, pues cubría la número 238.

Una vez establecida su cronología, pasaremos a describir el elemento. Los restos descubiertos consisten en un muro paralelo a la fachada meridional de la iglesia, cuya longitud es la misma de este paramento. Además, existían otros dos muros perpendiculares a la fábrica del templo. Uno de ellos - u.e. 259-, entregado a la arista oriental de la pared de mediodia, y el otro -u.e. 163- a la pared sur. La segunda de estas paredes era la que mejor se conservaba. Construida con unos cimientos potentes, tenia tres hiladas de obra vista, formada por sillares de tamaño mediano, bastante bien encuadrados. El muro paralelo de la fachada sur tenía el tramo central bastante arrasado, pero conservaba toda la cimentación y una hilada de piedra vista. En el lugar que coincidia con la puerta del templo, habia una piedra plana de gran tamaño que funcionaba como umbral.

Teniendo en cuenta estos hallazgos, podemos plantear la hipótesis de que el porche ocupaba una extensión igual a la longitud de la fachada de mediodía del templo, y que se hallaba subdividido en dos tramos, según indica el muro perpendicular situado entre la puerta y el contrafuerte actuales. Ignoramos cómo era la parte aérea, de la que no quedan restos. 
No obstante, suponemos dos posibilidades. Por una parte, la presencia de arcos, apoyados en un antepecho, como si se tratase de un claustro; esta disposición aparece en otros pórticos de la misma época ${ }^{11}$. Por otra parte, el hipotético porche podría no haber tenido arcos, y que el techo reposase sobre pilares ${ }^{12}$. Por lo que concierne a la cubierta, el muro perpendicular intermedio nos hace pensar que podria tener dos tramos de vigas paralelas a la fachada y sobre éstas se apoyarian las losas de coronamiento. Además, en la pared de la iglesia no se aprecian marcas de unas posibles vigas orientadas de norte a sur.

Esta estructura no funcionó demasiado tiempo, ya que su abondono se produjo al comienzo de la tercera fase, como tendremos ocasión de ver.

SEGUNDA FASE (1106- ca. 1300, lám. IV)

En 1106 tuvo lugar la consagración de la iglesia románica de Sant Vicenç de Rus. Esta fecha señala sus primeras transformaciones, que, aún manteniendo la estructura general, produjeron cambios notables. El templo continuó siendo de nave única y cabecera semicircular, pero el ábside se reconstruyó. Exteriormente aparecieron arcos ciegos, lesenas y una banqueta ornamental, y, en el interior, se ha descubierto una trinchera de fundación - u.e. 100-, cortando al estrato 103, el pavimento de la primera fase.

Las paredes laterales no fueron reconstruidas, pero sí ampliadas. Hemos estudiado el proceso mediante el análisis de la banqueta interior del muro meridional - u.e. 92-, la cual ha sufrido pocas alteraciones a lo largo de los años. También se ha tenido en cuenta su trinchera de fundación, que cortaba al estrato 103. Las paredes septentrional y occidental sufrieron una modificación parecida. La primera, cuya banqueta es la unidad 91 , no proporciona excesiva información, puesto que la roca natural se encontraba a la vista en este lado, y no hubo necesidad de practicar trinchera alguna. No obstante, la banqueta de la pared occidental -u.e. 112- también cortaba al estrato 103.

"Santa María de Basora, Ripollès, Girona (Junyent 1975: 189); Santa Magdalena de Guardiolans, Burgueda, Barcelona (BASTARDES, Vigué 1978: 204); Santa Lleïr de Casuella, Solsones, Lleida (VIDAL-VILASECA, 1979: 203).

${ }^{12}$ Sant Andreu de Castellcir, Vallès Oriental, Barcelona (JUNYET 1975: 192). 
La evolución arquitectónica de la iglesia de Sant Vicenç de Rus ...

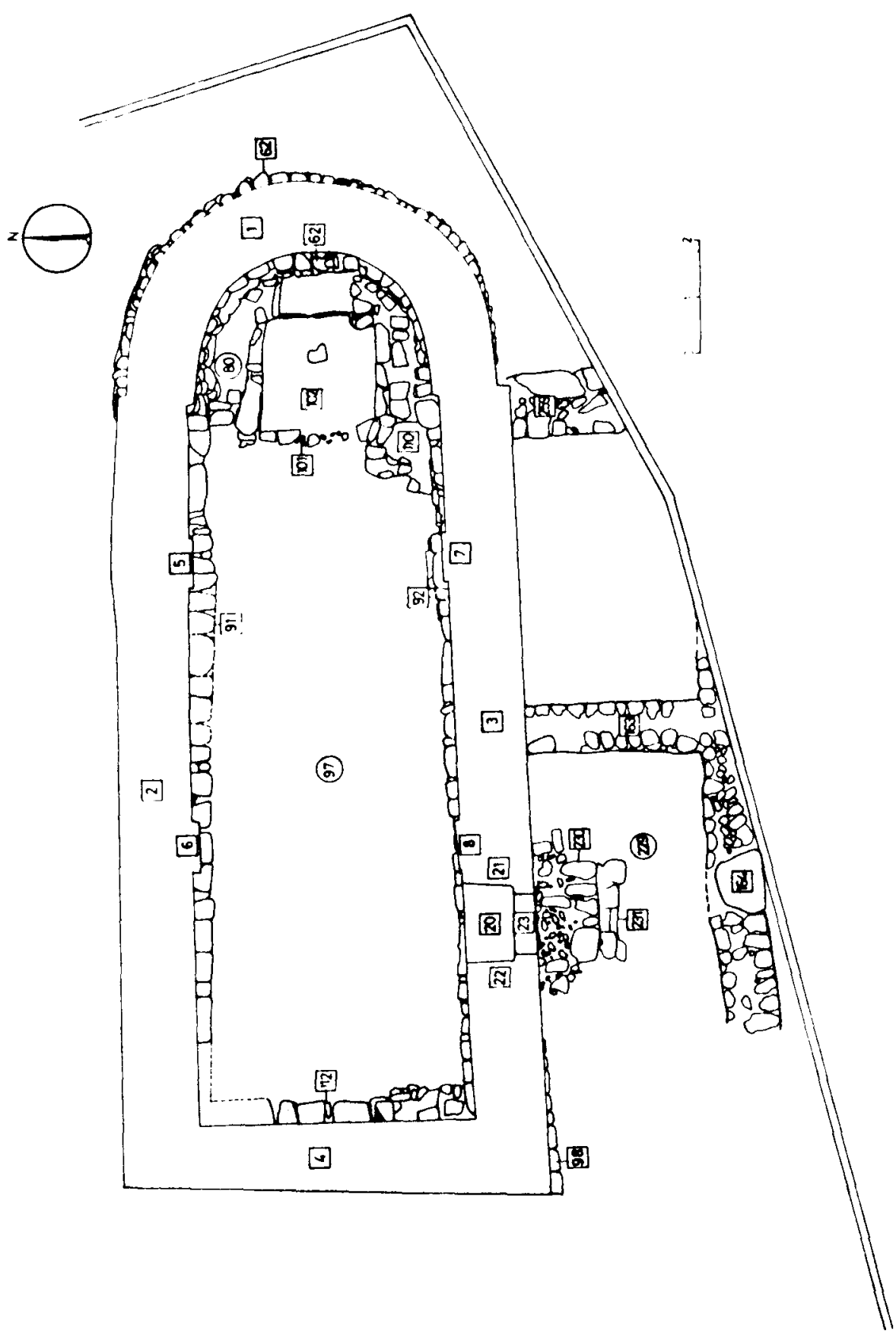

Lámina IV. Planta del edificio, después de su segunda consagración en 1106. 
Es lógico pensar que las modificaciones murarias descritas implicaran la construcción de una bóveda de medio cañón, reforzada por dos arcos fajones. Sobre esta bóveda, debió depositarse un relleno que sirviera de lecho a una cubierta de losas de pizarra. Durante la excavación, no se hallaron las losas en su posición original, pero su presencia se dedujo por el hallazgo de algunas que permanecian in situ en el alero del tejado; el supuesto relleno de tierras debió desaparecer al colocarse el último tejado que tuvo la iglesia antes de la restauración ${ }^{13}$. Estos cambios arquitectónicos se completaron con la decoración pictórica del ábside y con el enlucido interior del resto del templo. Los murales fueron hallados al iniciarse la restauración del edificio $y$, como deciamos, su estilo se ha asociado a la fecha de consagración de principios del siglo XII.

El pavimento que corresponde a esta época es el estrato 97. Se trata de un suelo de tierra batida mezclada con cal. Su excavación proporcionó algunos fragmentos informes de cerámica gris. Este estrato se entrega a una estructura presbiterial que cubre la trinchera de fundación n. ${ }^{\circ} 100$, a la cual hemos llamado unidad 110 . Por lo que se refiere al altar, los vestigios hallados indican que continuaba en uso el de la fase anterior. El escalón terminal del presbiterio también seguía siendo el mismo.

En el exterior del edificio, las extructuras correspondientes al pórtico de la fase anterior, continuaban en uso. Por otra parte, la necrópolis de la sagrera también se utilizaba, acumulándose nuevos enterramientos. Uno de ellos, la tumba $n .^{\circ} 41$, situada a poniente de la iglesia, estaba excavada en parte en una capa de arcillas - u.e. 38- que cubría una tumba antropomorfa anterior, la $\mathrm{n} .^{\circ} 39$, y en parte en la roca natural. En su interior se descubrio una olla de cerámica gris, datable a finales del siglo Xi o principios del XII. Otra pieza del mismo tipo se encontró en Montclar (Berguedà, Barcelona), en el interior de una inhumación ${ }^{14}$.

Debido a que la sepultura $n .^{\circ} 41$ estaba cortada por el muro n. 49 de la casa rectoral (ruinas de una construcción del siglo XVII, adosadas al templo antes de la restauración), no ha sido posible conocer su morfología exacta. No obstante, creemos que podría ser fusiforme o trapezoidal, según indica el perimetro de los restos de la fosa que se han documen-

${ }^{13}$ Durante el desmontaje del campanario, se descubrio un documento, contemporaneo de su ultima reparación, que ostentaba un epigrate de la Diputacion Provincial de Cataluna. fechable entre 1820 y 1833 .

14 Bolos 1985: 318. 
tado. Es interesante recordar que esta tumba se hallaba excavada a medias en la roca y en un estrato artificial de arcillas. Ello indica que, en un lugar con poco sedimento útil para colocar las sepulturas - donde el terreno virgen prácticamente afloraba-, las tumbas también podian excavarse en la roca, aunque esta técnica ya estuviera desfasada. La escasa potencia de esta zona también justificaria la reutilización a la que fueron sometidas las tumbas más antiguas, y que, quizás, ya se iniciara en esta época.

TERCERA FASE (ca. 1300-último cuarto del siglo xvII, lám. V)

Esta etapa se caracteriza por la presencia del pavimento 85, un suelo formado por arcillas y cal, que en el presbiterio se apoyaba sobre una preparación de piedras. Este estrato cubría directamente al n. 97 que, como hemos visto, era el pavimento de la fase anterior.

Una de las transformaciónes más significativas de este momento es la construcción de dos capillas laterales, situadas simétricamente a poniente del arco triunfal de la cabecera. Estos dos altares nuevos implicaron el adelantamiento hacia occidente del límite del presbiterio. Tal hecho propició que se ampliase considerablemente el área reservada al oficiante, restando espacio al lugar que ocupaba los fieles durante la celebración litúrgica. La capilla del lado del Evangelio -u.e. 9-, estaba dedicada a San Andrés, según se desprende de las fuentes documentales y de la seguridad de saber que la capilla n. ${ }^{\circ} 13$, colocada enfrente, se utilizaba para rendir culto a Santa María Magdalena.

En esta última se han descubierto pinturas murales, cuyo estilo indica una fecha de principios del siglo XIV ${ }^{15}$, acorde con la cerámica gris informe encontrada en el estrato 85. Por otra parte, la documentación ayuda a perfilar esta cronologia. Sabemos que el año 1312 ya se cita la existencia de las capillas. En 1323 existia un sacerdote que se ocupaba de la de Santa Magdalena. En 1391 se citan otra vez los altares de Santa Magdalena y San Andrés, así como el de San Vicente ${ }^{16}$.

La construcción de estos dos santuarios también fue consecuencia de dos cambios importantes en la morfología exterior de la iglesia: la edificación de contrafuertes y la desaparición del porche que funcionaba

Salva, Bargalló, 1989.

SUREDA 1984: 177. 


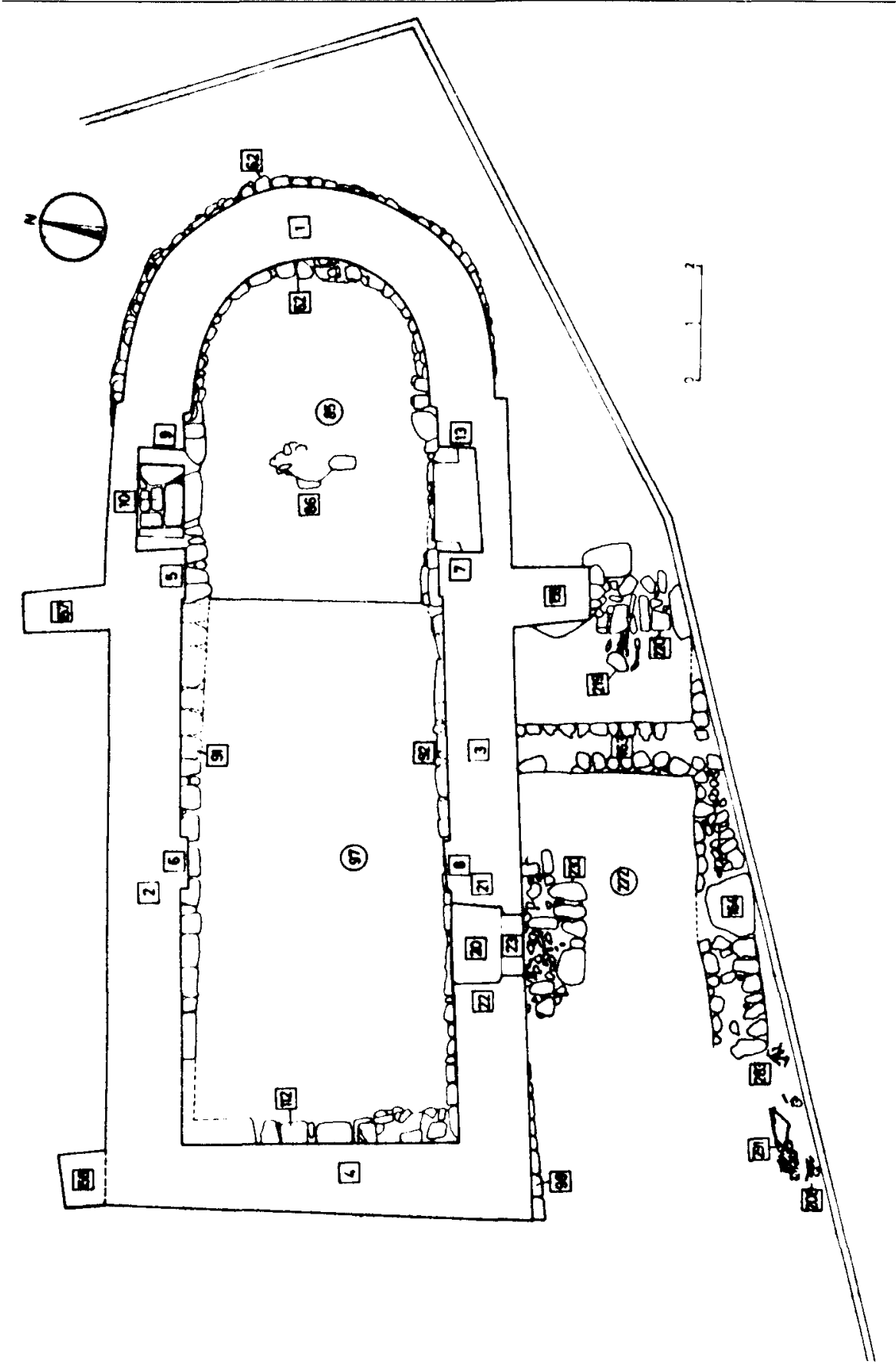

Lámina $V$. Planta de la iglesia en el momento de realizarse las reformas de ca. 1300, inmediatamente antes de la desaparición del porche. 
desde el siglo $\mathrm{xI}$. Suponemos que el segundo hecho fue subsidiario del primero. La excavación del entorno de la fachada de mediodia del templo ha proporcionado el descubrimiento de la cimentación de uno de los contrafuertes, el número 159. Sobre estos cimientos se encontraron algunas tumbas, así como otra debajo suyo. Esta última, antropomorfa excavada en la roca - u.e. 281-, estaba cortada por la construcción del contrafuerte y proporcionaba un indicio cronológico, aunque muy impreciso. No obstante, una de las tumbas depositadas sobre los cimientos - u.e. 218-, daba una información mucho más fiable. Era una inhumación orientada de este a oeste, quizás de un peregrino, pues en su interior se encontraron dos conchas de cardium, pero también contenia una moneda de Jaime II (1291-1327), lo que resultaba muy revelador. Indicaba que durante el reinado de este monarca el contrafuerte ya existía.

Esta datación corresponde casi exactamente a la de las pinturas de la capilla de Santa Maria Magdalena y a una de las informaciones documentales. Por ello suponemos que, al construirse las dos capillas, se creyó conveniente reforzar las paredes del templo y se erigieron los elementos de apoyo lateral.

Esta transformación también implicó una reforma del tramo de la bóveda de la nave que coincidia con la anchura de las repetidas capillas. Al limpiarse las paredes del templo en el curso de la restauración, hemos podido ver un escalonamiento en el extremo de poniente de esta parte de la bóveda. También, como resultado de estos trabajos, hemos observado que las paredes laterales del templo. en la zona de las capillas son algo más anchas y en su límite oriental se entregan a los estribos del arco triunfal de la cabecera, anulándolos en parte. Este hecho hace pensar que, acaso, la construcción de las estructuras que estudiamos, además de implicar retoques en las paredes laterales, ocasiono una modificación en la cubierta. En este supuesto los contrafuertes tendrían una clara razón de $\operatorname{ser}^{17}$.

En la nave propiamente dicha, las modificaciones no fueron demasiado numerosas. La más importante es un recorte de su longitud útil, pero debe destacarse que el pavimento 85 se entregaba a la cúspide de las banquetas de cimentación de las paredes perimetrales --u.e. 91, 92 y 112-; esto quiere decir que durante esta fase las banquetas continuarían desempeñando las funciones de bancos corridos, y que seguramente

Puig I Cadafalch, Falguera, Goday: 293. 

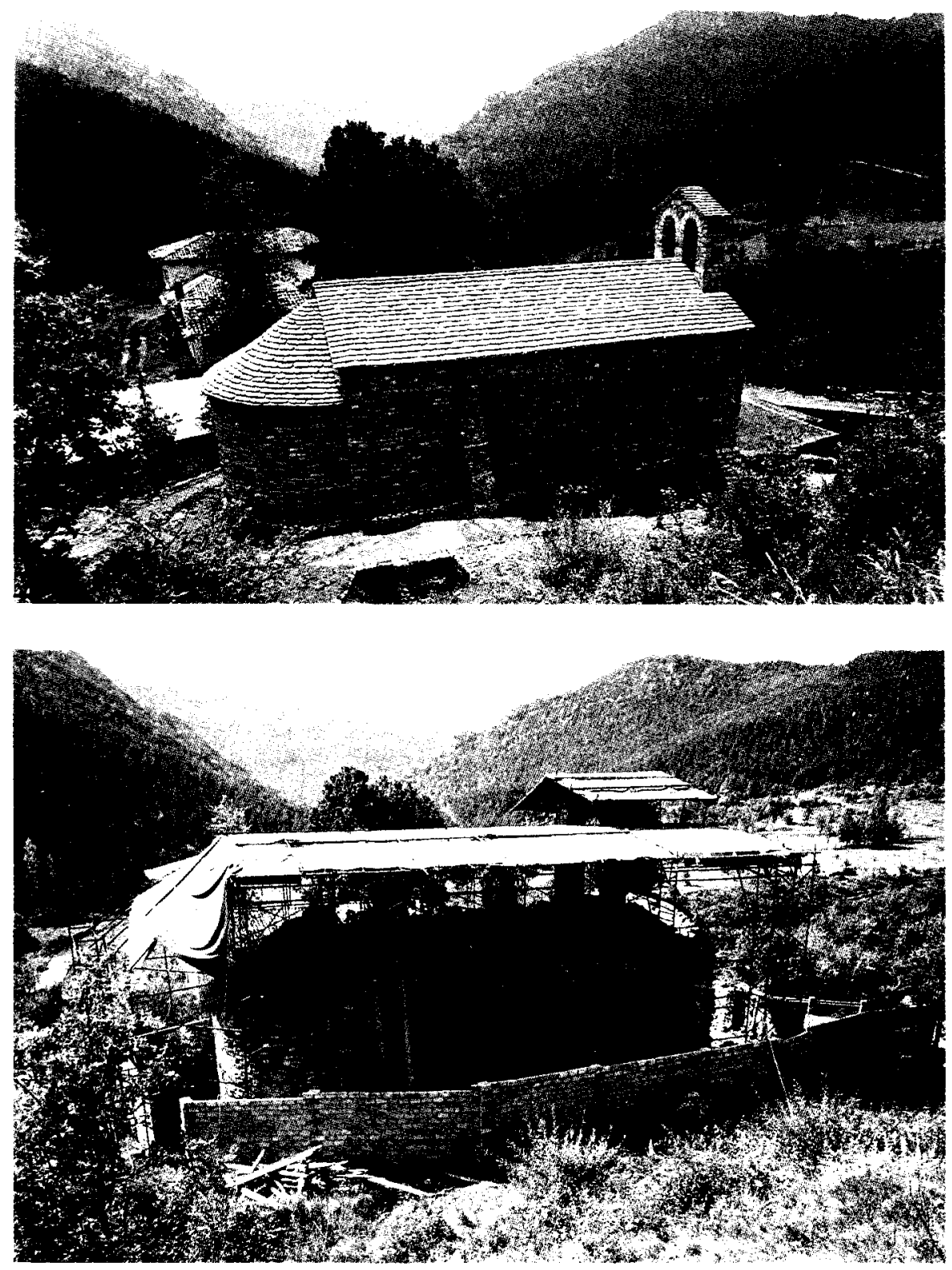

Lámina VI. 1. Vista general del edificio desde el norte, durante el proceso de excavación y restauración. 2. Vista desde el mismo punto, una vez finalizadas las obras. 
eran los únicos asientos que los fieles podian utilizar en los oficios religiosos.

Ya hemos apuntado que el presbiterio se ampliaba considerablemente, al hacerse más corta la nave, pero hay que añadir que el altar cambió de emplazamiento durante este período. La estructura primitiva, llamada unidad 102, empleada durante la segunda fase, fue abandonada y cubierta por el estrato 85. Para sustituirla, se construyó un nuevo altar: u.e. 86. No podemos hacernos una idea clara de su apariencia, ya que se encontró arrasado. Sin embargo, es evidente que el elemento 86 se hallaba más al oeste que el 102, a consecuencia del adelantamiento del escalón terminal del presbiterio. De este modo, el altar pasó a estar centrado entre las dos nuevas capillas de Santa Magdalena y San Andrés.

En el exterior del templo, una vez establecido que los contrafuertes son de principios de siglo XIV, también habriamos de suponer que en este momento se abandona el porche. Esto lo intuimos a través de la cerámica gris del estrato 222, la capa que amortizó la estructura, pero la misma existencia del contrafuerte, situado de lleno en el área donde debería estar el porche, también es indicativa. Por lo que se refiere a la puerta de entrada, hemos visto que durante la fase anterior se hallaba precedida de un escaloncito y un rellano, llamados unidades 230 y 231 , respectivamente. La amortización del pórtico, para la que fue necesario depositar el estrato número 222, hizo que desapareciera el escalón número 231 y que en este momento sólo quedase a la vista el rellano número 230 .

A lo largo de esta fase, en la sagrera del templo continuó el uso funerario. Los enterramientos siguieron practicándose en los alrededores de la iglesia, pero con un rito tan simple que no permite alardes tipologicos. Las tumbas continúan siendo de inhumación y su orientación es de este a oeste con la cabecera a poniente. La disposición de los individuos y el hallazgo de fosas muy simples, indican que durante esta fase ya habia abandonado la costumbre de enterrar en cistas, y que quizás se colocaba al difunto directamente en la fosa, pues en el interior de las tumbas no se han encontrado restos de clavos.

Esta rápida visión de los resultados de la excavación de Sant Vicenç de Rus, pone de manifiesto las transformaciones acaecidas en un pequeño templo rural del Prepirineo catalán durante la Edad Media. La pobreza de los materiales y la escasa entidad de los cambios realizados hablan bien a las claras de una sociedad de economia agropecuaria muy poco desarrollada, que trató de adaptar su iglesia parroquial a las corrien- 

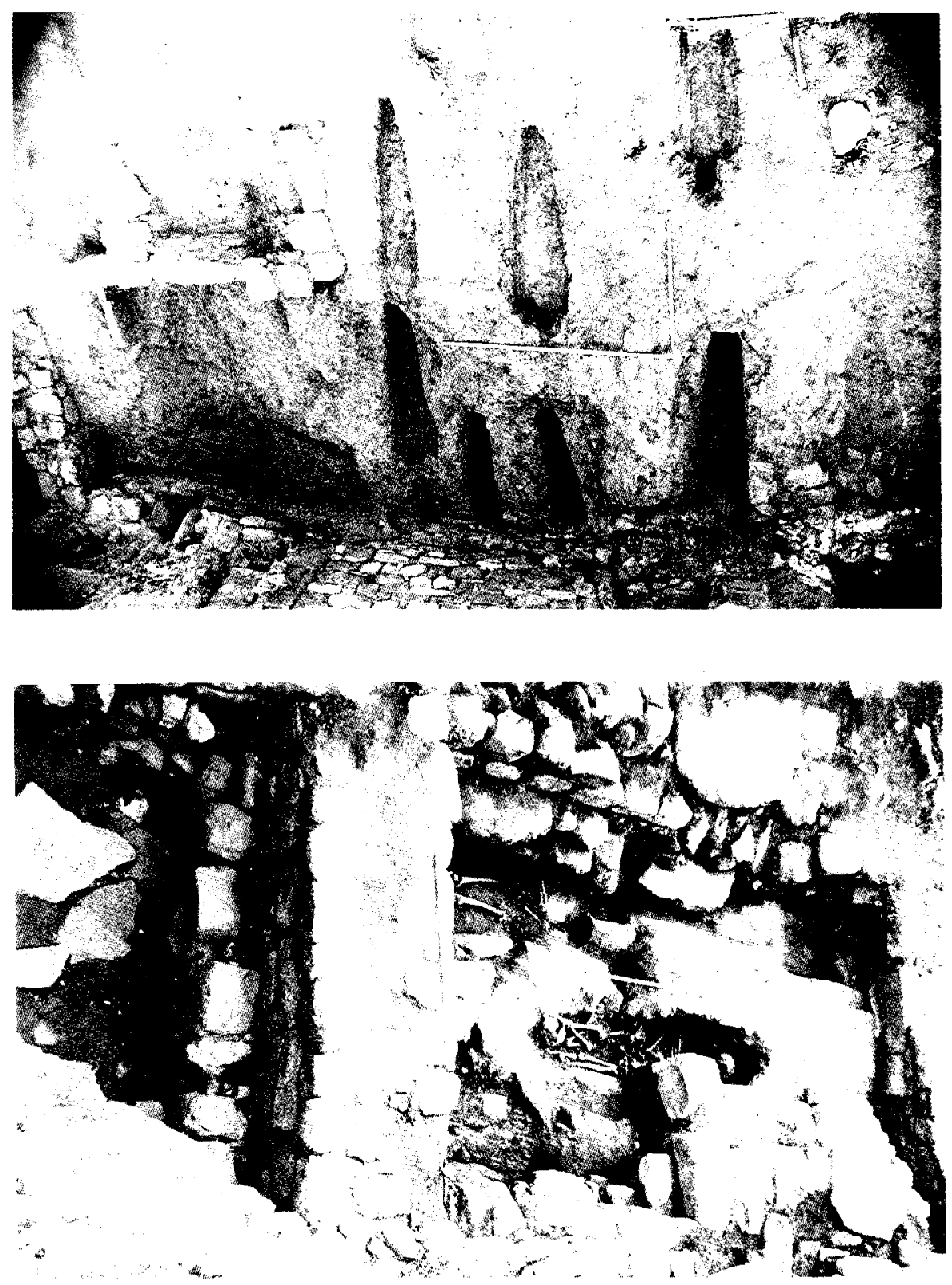

Lámina VII. 1. Vista parcial de la zona de poniente de la sagrera con algunas tumbas excavadas en la roca. 2. Estructuras de la galilea adosada a la fachada meridional, $y$ algunas sepulturas antropomorfas anteriores. 
La evolución arquitectónica de la iglesia de Sant Vicenç de Rus ...
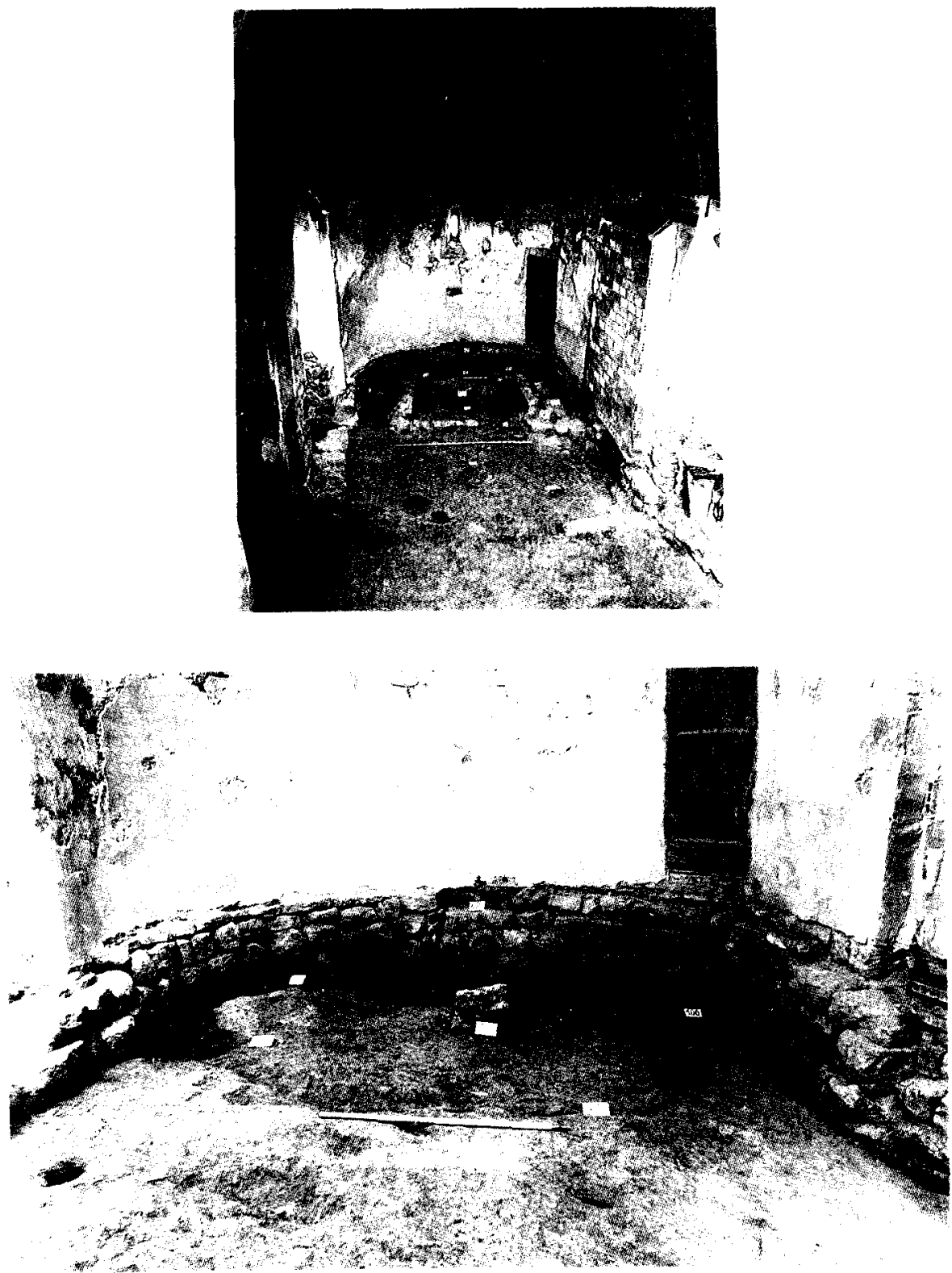

Lámina VIII. 1. Aspecto general de la iglesia desde poniente durante la excavación; pueden observarse estructuras correspondientes al siglo XII. 2. El estrato fundacional 103, cortado por la banqueta del ábside de 1106. 

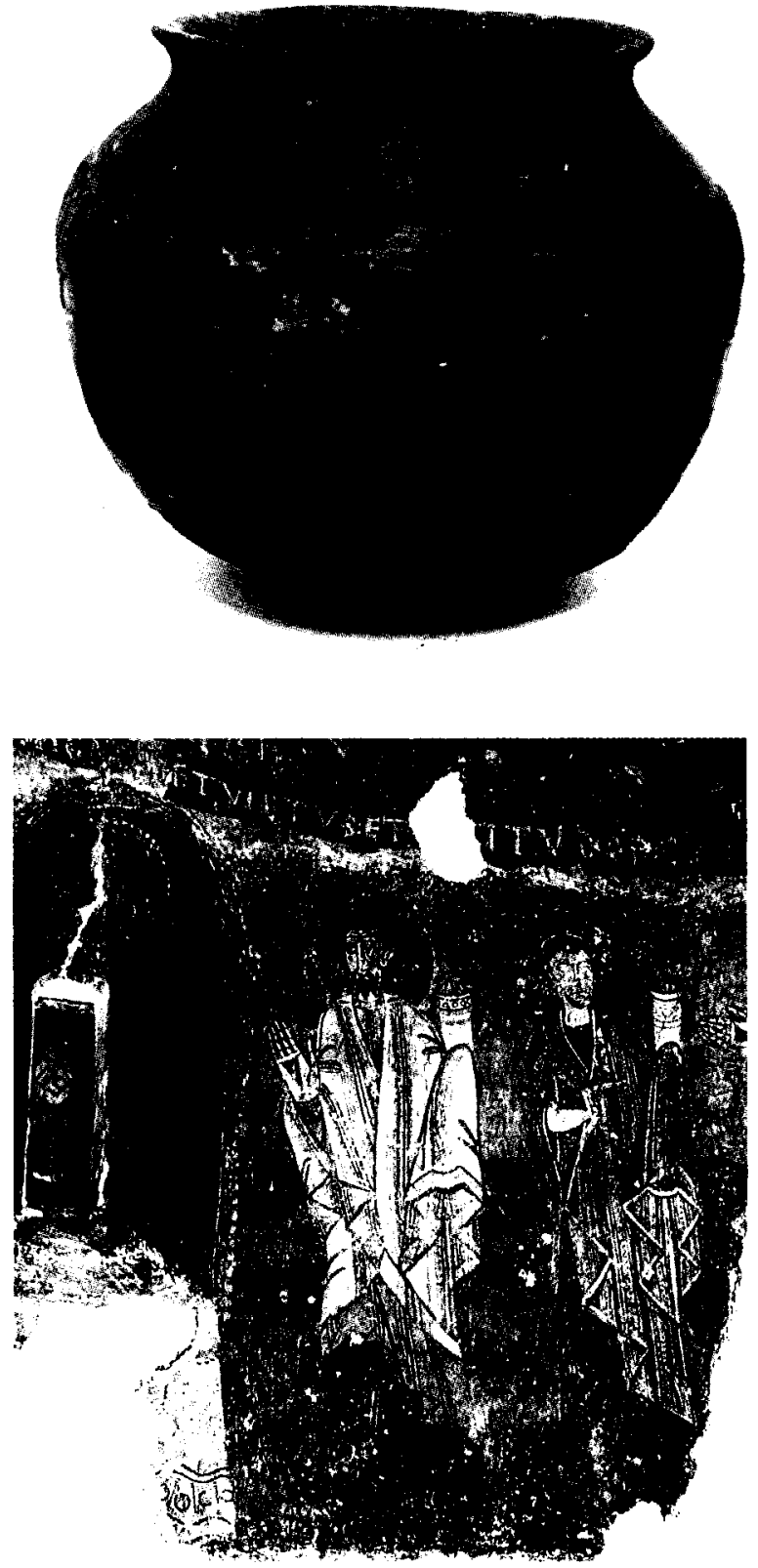

Lámina IX. 1. Detalle de las pinturas románicas descubiertas en el ábside. 2. Olla de cerámica gris que constituia el ajuar de la inhumación 39. 
tes artísticas más novedosas. El lector interesado por los pormenores de la evolución del edificio en épocas más tardías puede encontrarlos en una monografía de reciente publicación ${ }^{18}$, ya que, como es habitual en nuestros trabajos, la investigación afectó por igual a las estructuras y estratos medievales, modernos y contemporáneos.

18 Lopez Mullor, 1989. 


\section{BIBLIOGRAFIA}

Ainaud De LASARTE, J., 1989: Les pintures murals romàniques de l'església de Sant Vicenç de Rus, en LOPEz Mullor, A. Ed. Recerques històrico-arqueológiques al Berguedà (1983-1986). 1. Església de Sant Vicenç de Rus.

Baraut, C., 1978: "Les actes de consagracions d'esglésies del bisbat d'Urgell (segles $|x-x|$ )", en Urgellia, I.

- 1979: "Els documents dels segles Ix i x conservats a l'Arxiu Capitular de La Seu d'Urgell», en Urgellia, II.

Bastardes, A., Vigue, J., 1978: Monuments de la Catalunya Romànica. El Berguedà, 1, Barcelona.

Bolos, J., 1985: "Sepultura de Sant Martí de Montclar», en Catalunya Romànica, XII. El Berguedà, Barcelona.

Bolos, J.; PAGES, M., 1982: "Les sepultures excavades a la roca» en Acta Mediaevalia, Anexo I, Barcelona.

Fierro, J., 1988: “Excavaciones en la iglesia de Sant Marçal de Terrassola (Torrelavit, Barcelona)» en // Congreso de Arqueologia Medieval Española. Madrid, 1987.

Junyent, E., 1975: Catalunya Romànica, I, Barcelona 1975.

LOPEZ Mullor, A., 1984 a: "Església de Sant Vicenç de Malla (Il Fase) Les fonts arqueologiques", en Memòria 1983, Servei de Catalogacio i Conservació de Monuments de la Diputació de Barcelona, Barcelona.

- 1984 b: «Església de Sant Vicenç de Torelló. La recerca arqueològica", en Memória 1983, SCCM Diputació de Barcelona, Barcelona.

- 1984 c: "Església de Sant Vicenç de Rus. La recerca arqueològica", en Memória 1983, SCCM Diputació de Barcelona, Barcelona.

- 1984 d: "Sant Vicenç de Malla», en Catalunya Romànica. II. Osona I, Barcelona. 
La evolución arquitectónica de la iglesia de Sant Vicenç de Rus ...

- 1985: "Sant Vicenç de Rus", en Catalunya Romànica. XII. El Berguedá, Barcelona.

- 1986: "Sant Vicenç de Torelló", en Catalunya Romànica. III. Osona II, Barcelona.

- Ed. 1989: Recerques histórico-arqueològiques al Berguedá (19831986) 1. Església de Sant Vicenç de Rus.

Puig y Cadafalch, J.; Falguera, A.; Goday, J. 1983 (2. ${ }^{a}$ ed.): L'arquitectura romànica a Catalunya, II, Barcelona.

RuI, M., 1982: "Alguns costums funeraris de I'Edat Mitjana a Catalunya», en Acta Mediaevalia, Anexo 1, Barcelona.

Salva, M. G., Bargallo, E., 1989: "Les pintures murals de la capella de Santa Maria Magadalena", en LOPEz MulloR, A. Ed. Recerques històrico-arqueológiques al Berguedà (1983-1986). 1. Església de Sant Vicenç de Rus.

SuREDA M. J., 1984: «Església de Sant Vicenç de Rus. Les fonts documentals», en Memòria 1983, SCCM Diputació de Barcelona, Barcelona.

VIDAL-VILASECA, A., 1979: El romànic del Solsonès, Barcelona. 
